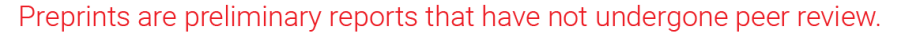 They should not be considered conclusive, used to inform clinical practice, or referenced by the media as validated information. \\ Enteral Nutrition Practices in Children with Cancer admitted into a Paediatric Intensive Care Unit and Clinical Outcomes
}

\section{Wanelia Afonso}

INCA

\section{Wilza Peres}

Universidade Federal do Rio de Janeiro

Nivaldo Pinho

INCA

\section{Renata Martucci}

INCA

\section{Daúbia Saraiva}

Inca

Patricia Padilha ( $\square$ patricia@nutricao.ufri.br)

Universidade Federal do Rio de Janeiro

\section{Research article}

Keywords: nutritional therapy, enteral nutrition, paediatrics, paediatric intensive care unit, cancer, mechanical ventilation

Posted Date: April 30th, 2020

DOl: https://doi.org/10.21203/rs.3.rs-22022/v1

License: (9) This work is licensed under a Creative Commons Attribution 4.0 International License. Read Full License 


\section{Abstract}

Background and Aim: Delays in both the prescription of, as well as interruptions in the administration of ENT, have been widely investigated. The most common reasons for damage in the nutritional impairment in children in a PICU are the presence of gastrointestinal disorders, together with medical and nursing procedures. This study aims to describe enteral nutrition practices in children with cancer and to evaluate the factors related to clinical outcomes, hospitalisation time (HT) and mechanical ventilation time (MVT), in a Paediatric Intensive Care Unit (PICU) of an Oncological Treatment Centre in Rio de Janeiro, Brazil.

Method: It is a retrospective longitudinal study, with children that were admitted into the PICU during 2013. Those children who had been diagnosed with a malignancy, aged 1 to 18 years, HT > $72 \mathrm{~h}$, as well as with the use of enteral nutrition therapy (ENT) during their hospitalisation in the PICU, were included in the study. The controlled variables were severity, age, caloric deficiencies, cumulative proteins, gastrointestinal symptoms and the early initiation of ENT. The odds ratios between the exposure factors were estimated with a confidence interval $(\mathrm{Cl})$ of $95 \%$ and a significance level of $p<0.05$.

Results: The study selected 54 patients; the median age was $8.02(2.35-12.79)$ years. The cumulative deficiencies of calories and proteins were $21.5(14.0-29.6) \mathrm{kcal} / \mathrm{kg} /$ day and $0.60(0.33-0.97) \mathrm{g} / \mathrm{kg} /$ day, respectively. Diarrhoea and younger age and the cumulative caloric deficiencies were HT predictors. Abdominal distention and younger age were associated with a higher MVT.

Conclusions: Changes in the gastrointestinal tract, with evaluation of the cumulative caloric deficiencies in critically ill children with cancer, should be monitored more continuously, as well as with the impact of these variables on the HT and MVT outcomes.

\section{Background}

There are only a few studies about Enteral Nutritional Therapy (ENT) of children in a Paediatric Intensive Care Unit (PICU). However, there is a consensus by the staff, for a much greater role of ENT, as well as for seeking an optimal nutritional therapy for these types of malignant patients. Any adoption of these practices would be to minimise the nutritional deficiencies. They would also contribute to improving the clinical outcomes with prognoses for these critical situations. However, there is still a continual debate about what would be the ideal type of nutrition for these types of patients, Enteral Nutritional Therapy (ENT) or Parenteral Nutritional Therapy (PNT). ${ }^{1-3}$

ENT, as a nutritional interventional method for patients in an intensive care unit, has a greater acceptance than PNT. Therefore, as a result, most institutional protocols are based on this hypothesis. ${ }^{3-4-5}$ The main objective of ENT is to increase the short-term benefits of paediatric patients in response to stress, while at the same time, minimising the adverse consequences of malnutrition in the longer term. ${ }^{4-5}$

For children in an intensive care unit and for those with a functioning gastrointestinal tract, ENT has been recommended as the preferred option for a nutritional intervention in a PICU. However, based upon 
scientific evidence, this is considered to be of a low quality (level C) ${ }^{1-3}$ In order to achieve the objectives of ENT in a PICU, the procedure should be regarded as a precocious prescription. An early governance of ENT would be required in order to be assured of its proper administration. ${ }^{6}$

Delays in both the prescription of, as well as interruptions in the administration of ENT, have been widely investigated. The most common reasons for damage in the nutritional impairment in children in a PICU are the presence of gastrointestinal disorders, together with medical and nursing procedures. These situations can be averted and should be avoided in any administration of ENT. ${ }^{2-6-7-8}$

Gastrointestinal complications, as diarrhoea, constipation and abdominal distension, are associated with the effectiveness of ENT and these may affect the clinical outcomes in a PICU. The frequency of complications can vary greatly in a population of critically ill patients, this rate ranges from between $50 \%$ $-62 \%{ }^{9}$

Thus, this study aims to describe enteral nutrition practices in children with cancer and to evaluate the factors related to clinical outcomes, hospitalisation time (HT) and mechanical ventilation time (MVT), in a PICU of an Oncological Treatment Centre in Rio de Janeiro, Brazil.

\section{Methods}

\section{Design and Study Population}

This was a retrospective longitudinal study, whose population consisted of children and adolescents admitted to the PICU of a reference centre for the treatment of cancer patients in Rio de Janeiro, Brazil, from January to December 2013. All of the children and adolescents were diagnosed with a malignancy. They were aged 1 to 18 years old and they made use of ENT during their hospitalisation in the PICU during the year 2013. Those patients who were palliative and receiving end of life care and those patients who needed an exclusive use of an oral diet and/or those requiring parenteral nutrition therapy during their hospitalisation in the PICU were excluded.

\section{Data Collection}

The data was collected from the physical and electronic records of patients through a form that was prepared solely for this research. In order to characterise the demographic and clinical data, the study used hospital registration information, the age of the patients in years and months, their gender, their admission date, their discharge date, the reasons for their hospitalisation, their use of vasoactive drugs in the PICU, their mechanical ventilation time (MVT) details and their ENT information. The patient's use of vasoactive drugs (amines) and sedatives were defined as the categorical variables.

\section{Anthropometry}


Anthropometrical assessments of their nutritional status on admission to the PICU used their body mass index for age (BMI/A) calculated by their body weight in kilogrammes and their height in metres, by dividing their weight by their height squared (weight $(\mathrm{kg}) \mathrm{x}$ height $\mathrm{m}^{2}$ ). Subsequently, their $Z$ scores of BMI/A were calculated by WHO Anthro and Anthroplus Software Version 3.2.2., (using Anthro for those children up to 5 years old; and using Anthroplus for those children over 5 years of age, together with the adolescents up to 18 years). ${ }^{12}$

The cut-off points for their BMI classification were below appropriate (low weight and nutritional risk) $<-1$ z score; appropriate $>-1$ and <+ 1 DP z score; and overweight $>+1$ SD z score. ${ }^{13}$

\section{Mortality Prognostic Index - Paediatric Risk of Mortality (PRISM)}

The evaluations of the prognostic index of mortality, called the Paediatric Risk of Mortality (PRISM) score

14, were considered as having being registered in the PICU report by the medical paediatric intensivist. The data was expressed in points.

\section{Nutritional Needs}

The estimates for energy and protein requirements, collected from the medical records held by the nutritionist responsible for the PICU, were calculated according to the formula of Holliday-Segar's equation and the American Society for Parenteral and Enteral Nutrition's (A.S.P.E.N) Board of Directors' clinical guidelines and adapted by Garofalo, respectively. ${ }^{3-15-16}$ This PICU also adopted the protocols defined as recomendadion by Consensus of the Instituto Nacional de Cancer (INCA) ${ }^{17}$

\section{Enteral Nutritional Therapy}

- Early Nutrition: This was defined as the initiation of ENT, 48 hours after the admission to the PICU. The study considered the date and the time that the patient was admitted to the PICU (for hours counting down to the start of the ENT procedure). ${ }^{18}$

- Cumulative Energy Deficit: This was obtained by the differences between the caloric needs by age and the estimated energy from the ENT procedure that was received by the patient. The study categorised this as $<$ median and $\geq$ median. ${ }^{19}$ The total deficit of energy was divided by the patient's weight and the number of days spent in the ENT procedure, with the cumulative deficit displayed as calories $/ \mathrm{kg} /$ day. - Cumulative Protein Deficit: This was obtained by the differences between the estimated protein needs by age and the proteins from the Enteral Nutritional Therapy received by the patient. The study categorised this as $<$ median and $\geq$ median. ${ }^{19}$ The total deficit of proteins was divided by the patient's weight and the number of days spent in the ENT procedure, with the deficit displayed as protein $/ \mathrm{kg} / \mathrm{day}$. - Diarrhoea Frequency: This was defined as in order to reduce the consistency of the bowel movements (liquid or semi-liquid) and with an increased frequency of 3 or more bowel movements within 24 h. ${ }^{20}$ The variables were categorised as yes or no (that was the presence or the absence of these symptoms that were recorded in the chart). 
- Episodes of Constipation Frequency: These were defined as being less than three bowel movements per week. ${ }^{4}$ They were categorised as yes or no (that being the presence or the absence of these symptoms as recorded in the medical records during their hospitalisation in the PICU).

- Frequency of Episodes of Abdominal Distension: These were categorised as yes or no (that being the presence or the absence of these symptoms that were recorded by the doctor in the medical records during their hospitalisation in the PICU).

- Frequence of intolerance to the diet: This was defined as vomiting, nausea, diarrhea, abdominal distension, etc.

- Age: This was categorised as below or equal to the median (that being $<8$ years and $\geq 8$ years).

\section{Clinical Outcomes}

The clinical outcomes that were considered were HT and MVT. HT was defined by the number of days of hospitalisation from the date of admission to the PICU until being discharged from the unit. MVT was regarded as the number of days on mechanical ventilation during their hospitalisation in the PICU.

HT was divided into less than 14 days, or greater than, or equal to 14 days. MVT was categorised as being less than 7 days, or greater than, or equal to 7 days.

\section{Data Analyses}

After the collection of information from the medical records, the forms were reviewed by the researchers in order to minimise the errors and to establish the lack of relevant data. The data was then entered into Statistical Package for Social Sciences (SPSS) Software for Windows Version 23.0.

The variables were expressed as percentages, medians and interquartile ranges. The data analyses were carried out in two steps: (1) bivariate analyses using the Chi-Square test; (2) multivariate analyses using the logistic regression method.

The multiple regression models of the variables in the bivariate analyses showed a less than significant value of 0.20 , according to the recommendations of Hosmer-Lemeshow ${ }^{21}$. These models were conducted in order to reveal which factors were most strongly associated with HT and the outcomes of MVT. In the final models, those variables that were associated with the dependent variables were at a level $<0.05$. In the logistic regression method, the odds ratios between the exposure factors were estimated, with a confidence interval $(\mathrm{Cl})$ of $95 \%$.

\section{Ethical Aspects}

The study followed the rules laid down in Brazilian ethics resolution. They were approved by the Ethical Comitee of the University Hospital Clementino Fraga Filho (HUCFF) and the INCA, under the protocols 37601214.5.0000.5257 and 37601214.5.3001.5274, respectively. The ethics committee was asked to dispense the consent form, because it was used data from the medical records, and the need for consent was waived because the researchers signed the data usage agreement, as required by Brazilian ethics resolution 466/2012 (Brasil, 2012). 


\section{Results}

The final sample consisted of 54 children and adolescents that were selected in the study as shown in Fig. 1. The median age was $8.02(2.35-12.79)$ years; $50 \%(n=27)$ were femele and median time from oncology diagnosis to admission was $0.04(0.02-1.02)$ years. The most common treatment modality to which the patients were undergoing was chemotherapy $(30.8 \%, n=16)$. The main reason for ICU admission was: respiratory failure $(26.4 \% ; n=14)$ and sepsis $(24.5 \% ; n=13)$. The PRISM median was $4.95(n=47 ; 1.45-15.73)$ points, and all patients were mechanically were ventilated. Table 1 presents the characteristics of the study's population. 
Table 1

Sociodemographic, Clinical, and Anthropometrical Characteristics, of Children and Adolescents treated in a Paediatric Intensive Care Unit of a Reference Centre for Oncological Treatment, in Rio de Janeiro, Brazil.

\begin{tabular}{|c|c|}
\hline Variables (n) & Median (IQR) or \% (n) \\
\hline Age (years; $n=54)$ & $8.02(2.35-12.79)$ \\
\hline \multicolumn{2}{|l|}{ Gender $(n=54)$} \\
\hline Female & $50(n=27)$ \\
\hline Male & $50(n=27)$ \\
\hline \multicolumn{2}{|l|}{ Type of Tumour $(n=54)$} \\
\hline Haematological & $7.4(n=4)$ \\
\hline Solid Tumours & $92.6(n=50)$ \\
\hline PRISM (Points) & $4.95(1.45-15.73)$ \\
\hline \multicolumn{2}{|l|}{ Type of Treatment $(n=52)$} \\
\hline Chemotherapy & $30.8(n=16)$ \\
\hline Radiotherapy & $1.9(n=1)$ \\
\hline Surgery & $17.3(n=9)$ \\
\hline No Treatment & $17.3(n=9)$ \\
\hline Control & $3.8(n=2)$ \\
\hline More Than One Method & $28.9(n=2)$ \\
\hline \multicolumn{2}{|l|}{ Diagnosis at ICU Admission $(n=53)$} \\
\hline Sepsis & $24.5(n=13)$ \\
\hline Reduced level of consciousness & $17.0(n=9)$ \\
\hline Respiratory failure & $26.4(n=14)$ \\
\hline Postoperative & $20.8(n=11)$ \\
\hline Others & $11.3(n=6)$ \\
\hline Nutritional Status According to BMI/Age $(n=51)$ & $23.0(14.35-36.75)$ \\
\hline Underweight & $23.5(n=12)$ \\
\hline Adequate & $47.1(n=24)$ \\
\hline Overweight & $29.4(n=15)$ \\
\hline
\end{tabular}

IQR: Interquartile Range; BMI: Body Mass Index; PICU: Paediatric Intensive Care Unit. 


\begin{tabular}{|ll|}
\hline Variables $(\mathbf{n})$ & Median (IQR) or \% $(\mathbf{n})$ \\
\hline Vasoactive Drugs $(\mathbf{n}=\mathbf{5 3})$ & $37.7(\mathrm{n}=20)$ \\
\hline Yes & $62.3(\mathrm{n}=33)$ \\
\hline No & $64.2(\mathrm{n}=34)$ \\
\hline Use of Sedatives $(\mathbf{n}=\mathbf{5 3})$ & $35.8(\mathrm{n}=19)$ \\
\hline No & $11(6.0-18.0)$ \\
\hline Length of Stay in the PICU (days; $\mathbf{n}=\mathbf{5 4})$ & $11(6.0-16.86)$ \\
\hline Mechanical Ventilation Time (days; $\mathbf{n}=\mathbf{5 4})$ & \\
\hline IQR: Interquartile Range; BMI: Body Mass Index; PICU: Paediatric Intensive Care Unit. \\
\hline
\end{tabular}

Regarding the main practices of ENT, the nutritional assessments of all of the patients were recorded on a chart during the first 24 hours of admission. They demonstrated the percentages of weight deviation, according to the anthropometrical indicator of $\mathrm{BMI} /$ age; $52.9 \%$ of the patients were adequate $23.5 \%$ underweight and $29.4 \%$ overweight). The study showed that the median time to the initiation of enteral feeding was $27(21-55)$ hours and the frequency of an early ENT was in the first 48 hours in $70.4 \%$ ( $n=$ 38 ) of the patients. The routes of administration were by post pyloric tube $(n=46 ; 85.2 \%)$, by nasogastric catheter $(n=1,1.9 \%)$ and by gastrostomy $(n=7 ; 12.9 \%)$. As for the types of diet that were used to start the ENT procedures, the records highlighted a polymeric formula $(75.9 \% ; n=41)$. Table 2 shows a description of the factors that were related to the practices of ENT. The cumulative deficit of the calories and the proteins throughout their hospitalisation was $21.5(14.0-29.6) \mathrm{kcal} / \mathrm{kg} / \mathrm{day}$ and $0.60(0.33-0.97)$ $\mathrm{g} / \mathrm{kg} /$ day. 
Table 2

Descriptions of Nutritional Therapy Practices in a Paediatric Intensive Care Unit of a Reference Centre for Oncological Treatment, in Rio de Janeiro, Brazil.

\begin{tabular}{|c|c|}
\hline Variables (n) & Median (IQR) or \% (n) \\
\hline Start Time of ENT (hours; $n=54$ ) & $27(21-55)$ \\
\hline \multicolumn{2}{|l|}{ Route of Administration of ENT $(n=54)$} \\
\hline NEC & $85.2(n=46)$ \\
\hline NGC & $1.9(n=1)$ \\
\hline Gastrostomy & $12.9(n=7)$ \\
\hline Time of ENT(days; $n=54$ ) & $7(4-14.75)$ \\
\hline Time to Reach Full Nutritional Needs (days; $\mathrm{n}=35$ ) & $4(2.5-7.5)$ \\
\hline Percentage of Patients achieving Full ENT & $64.8(n=35)$ \\
\hline Enteral Nutrition-48 h & $92.6(n=50)$ \\
\hline \multicolumn{2}{|l|}{ Type of Starting Diet of ENT $(n=54)$} \\
\hline Polymer Formula & $75.9(n=41)$ \\
\hline Oligomeric Formula & $16.7(n=9)$ \\
\hline Elemental Formula & $7.4(n=4)$ \\
\hline Cumulative Caloric Deficit (kcal/kg/dia; n = 54) & $21.5(14-29.6)$ \\
\hline Cumulative Protein Deficit (g/kg/dia; n = 54) & $0.60(0.33-0.97)$ \\
\hline \multicolumn{2}{|l|}{ GIT Complication Frequencies $(n=54)$} \\
\hline Diarrhoea & $25.9(n=14)$ \\
\hline Constipation & $31,5(n=17)$ \\
\hline Abdominal Distention & $46.3(n=25)$ \\
\hline \multicolumn{2}{|l|}{ Interruptions Stopping the ENT(n = 35) } \\
\hline Exams & $17.1(n=6)$ \\
\hline Procedures & $28.6(n=10)$ \\
\hline Intolerance to the Diet & $20.0(n=7)$ \\
\hline Surgery & $8.6(n=3)$ \\
\hline Others & $25.7(n=9)$ \\
\hline
\end{tabular}


The bivariate analyses for the HT outcomes were evaluated as: lactate variables at admission $(p=0.257)$; the routes of the administrations of ENT $(p=0.204)$; the presence of diarrhoea $(p=0.001)$; the presence of abdominal distension $(p=0.034)$; the use of amines $(p=0.323)$; severity illness at admission $(p=0.150$ ); younger age $(p=0.004)$; the cumulative calorie deficit $(p=0.140)$; the cumulative protein deficit $(p=$ $0.180)$; and early enteral nutrition $(p=0.770)$. When considering the bivariate analyses for the MVT outcomes, the results were: lactate variables at admission $(p=0.395)$; the routes of the administrations of ENT $(p=0.039)$; the presence of diarrhoea $(p=0.005)$; the presence of abdominal distension $(p=0.001)$; the use of amines $(p=0.122)$; severity illness at admission $(p=0.004)$; younger age $(p=0.047)$; the cumulative caloric deficit $(p=0.129)$; the cumulative protein deficit $(p=0.157)$; and early enteral nutrition $(p=0.507)$.

The variables in the final models which resulted in predicting HT were diarrhoea, younger age and incresed cumulative caloric deficit in calories $/ \mathrm{kg} /$ day. The results have shown that those patients with diarrhoea were 29.4 times more likely to remain hospitalised for $>14$ days, as well as those that were at a younger age, were more likely to stay in hospital during this same period of time. For the other variables, no significant differences were observed. Table 3 describes the incidence density ratios of the hospital stay and the mechanical ventilation time outcomes.

Table 3

Incidence of Density Ratios of Hospital Stay Outcomes in the PICU and Mechanical Ventilation.

\begin{tabular}{|c|c|c|c|c|c|c|}
\hline \multicolumn{7}{|c|}{ Length of Stay in the PICU $\geq 14$ days } \\
\hline Variables (n) & $\beta$ & p & $\mathrm{Cl} 95 \%$ & OR & $\mathbf{p}$ & $\mathrm{Cl} 95 \%$ \\
\hline Presence of Diarrhoea & 3.37 & 0.003 & $1.12-5.63$ & 29.3 & 0.003 & $3.07-279.9$ \\
\hline Age & -0.35 & 0.002 & $0.57-0.34$ & 0.70 & 0.002 & $0.56-0.87$ \\
\hline Cumulative Caloric Deficit & -0.063 & 0.005 & $0.12-0.01$ & 0.93 & 0.005 & $0.88-1.00$ \\
\hline \multicolumn{7}{|c|}{ Ventilation Time in the PICU $\geq 7$ days } \\
\hline Age & -0.14 & 0.021 & $0.22-0.27$ & 0.86 & 0.021 & $0.76-0.97$ \\
\hline Presence of Abdominal Distension & 1.34 & 0.031 & $0.12-2.56$ & 3.84 & 0.031 & $1.13-13.04$ \\
\hline \multicolumn{7}{|c|}{$\begin{array}{l}\text { OR: Odds Ratio; } 95 \% \mathrm{Cl}: 95 \% \text { Confidence Interval; PICU: Paediatric Intensive Care Unit; References: } \\
\text { Age } \geq 8 \text { years; Cumulative Caloric Deficit: } \leq 21.5 \mathrm{Kcal} / \mathrm{Kg} / \text { day; Controlled Variables in the Models for } \\
\mathrm{HT} \text { were: the presence of diarrhoea; the presence of abdominal distension; the severity levels; age; the } \\
\text { cumulative caloric deficit; and the cumulative protein deficit. Controlled Variables in the Models for } \\
\text { MVT were: the route of administration of TNE; the presence of diarrhoea; the presence of abdominal } \\
\text { distension; the use of amines; the severity levels; age; the cumulative caloric deficit; and the } \\
\text { cumulative protein deficit. }\end{array}$} \\
\hline
\end{tabular}

\section{Discussion}


There can be no doubt that ENT is essential for the care of children with cancer in a Paediatric Intensive Care Unit and that an early use has been widely recommended. In this study, the start time of ENT was consistent with that found by other authors and was according to the recommendations by the quality indicators of the International Life Sciences Institute, which has suggested a target of $80 \%$ of children should received ENT in the first 48 hours of PICU admission. ${ }^{4}$

An observational study in two paediatric intensive care units in Europe, which the primary outcome used in this study was the percentage of target energy requirements achieved per day of the child's PICU stay, shows that There were no significant differences in the median percentage of energy targets achieved in the first 4 days of PICU admission. However Time to first feed (hours) mean was $7.84( \pm 7.38)$ in the PICU that mensure gastric residual volume. On the other hand, in the PICU that do not mensure gastric residual volume it was $21.5( \pm 18.3) .{ }^{22}$

In the literature, there is still a controversy over the appropriate time for the commencement of ENT. However, recent studies have compared the provisions of early versus late ENT on the outcomes most studied in critically ill patients, especially those of HT and MVT. ${ }^{7-23}$ The relationship between an early ENT and these outcomes could not be confirmed in this study, probably due to the limited number of patients. Due to the heterogeneity of the methods that were used in the studies and the characteristics of the PICU in question, most authors cited or discussed the relationships of early ENT with HT and MVT, although not all affirmed those associations. Similar results to this study were found by Mikhailov TA ${ }^{24}$, whose study also showed no significant associations of these kinds of relationships.

The proposed benefits of early ENT include: reducing the incidence of sepsis, intestinal trophism, immune system stimulation, preservation of the intestinal barrier and preventing bacterial translocation. ${ }^{3}$

Another relevant issue was the prescription of enteral formulas. An enteral diet should consider the nutritional status of the paediatric patients, their nutritional needs and their medical conditions. The prescriber must know the caloric densities, the osmolarities, and the contents of the macronutrients and the micronutrients, when prescribing the formulas. However, there is no consensus on the types of formula to be used. ${ }^{3-23}$

Regarding the placement of the catheter when used for the administration of ENT, in this study, the post pyloric position was used more often. The American Society for Parenteral and Enteral Nutrition suggests that there is no need to indicate the enteric positioning for those children in a Paediatric Intensive Care Unit, except for those suffering from gastrointestinal complications. ${ }^{3}$

López-Herce $\mathrm{J}^{9}$ has pointed out that often the child in an intensive care unit has a difficulty when tolerating gastric positioning, especially those MV patients, due to a reduced secondary gastric motility drug use, or the disease itself, coursing with abdominal distension and an increased gastric residue. These factors limit the scope of the full nutritional needs in paediatric critical patients. It is believed that an increase in these complications that are related to the gastrointestinal tract may negatively interfere 
with the clinical outcomes of these critically ill children, as the impact of diarrhoea and abdominal distension affects the HT and MVT outcomes, respectively, as has been shown in this study.

Vasoactive drugs may also reduce intestinal perfusion, affecting the tolerance of enteral feeding. Moreover, the need for sedatives, frequent in this study's population, can lead to a reduced gastrointestinal motility. ${ }^{9-25}$

There is no data on the frequency of constipation in paediatric critical patients. However, this complication may result from immobilisation, dehydration, drugs that influence the intestinal motility and the absence of fibre in a diet. ${ }^{9}$ Among the complications that are unrelated to the gastrointestinal tract and that are responsible for the interruption of enteral feeding, De Oliveira Iglesias ${ }^{5}$ highlighted haemodynamic instability (34.5\%), handling procedures (38\%) and an accidental loss of the enteral catheter $(27 \%)$. The authors found that the high frequency of procedures may also be reflected in difficulties when trying to achieve a full diet.

An inadequate supply of nutrients may also reflect a deterioration of the nutritional status of these patients, contributing to an increased frequency of malnutrition conditions that have been associated in various studies with an increased mortality, the length of stay, an increased number of organ dysfunctions and complications. ${ }^{3-26}$

Analyses of the cumulative caloric-protein deficiencies in children in a PICU in the Netherlands significantly associated these deficits in reducing the $Z$ scores for the anthropometrical indicators. ${ }^{27}$ Many indicators have revealed the barriers for a proper nutritional supply in a PICU, which contribute to a worsening nutritional status. Among these, the most frequently reported in the literature are: gastrointestinal disorders, breaks in procedures, and the restrictions of a water supply. ${ }^{23}$

A study by Manaf $Z A^{28}$, conducted with paediatric critical patients, with a median age of $10.2(5.1-50.5)$ months, found cumulative deficits of energy and proteins of $200 \pm 397 \mathrm{kcal} / \mathrm{kg}$ and $11.4 \pm 22.8 \mathrm{~g} / \mathrm{kg}$ in 14 days, respectively. The main factors that were associated with the deficits of nutrients were the frequency of interruptions in the nutritional therapy and the duration of the interruptions in feeding. Hulst $\mathrm{J}^{19}$, when analysing patients between 1 month and 18 years old, with the usage of energy and protein recommendations that were based upon the recommended Dietary Allowances (RDA) for age and gender, found that after 14 days in the PICU, the cumulative deficit of energy was $162 \pm 27 \mathrm{kcal} / \mathrm{kg}$ and the cumulative deficit of proteins was $2.4 \pm 0.8 \mathrm{~g} / \mathrm{kg}$ - and that these deficits were associated with the anthropometrical changes during their hospitalisation in the PICU. In this same study, the younger patients had a higher risk of cumulative caloric deficits, as well as HT and security, similar to the findings in this series .

In this context, a great discussion in clinical practices has been the determination of actual energy expenditure of this population, since the gold standard is indirect calorimetry and predictive formulas have questioned its accuracy when calculating the younger patients' nutritional needs. ${ }^{29-30}$ However, the 
recommendations of health committees has been for the use of prediction formulas, in the absence of any indirect calorimetry. ${ }^{3}$

In a multicentre study that was conducted in a different PICU with 31 children undergoing an MV procedure, an energy supply of at least $66.7 \%$ of their enteral energy needs was associated with a reduced mortality over 60 days. Among the factors that are associated with higher energy percentages of receiving patients on enteral nutrition are: younger children, an increased length of stay in the PICU, a shorter duration of MVT, the reasons for a clinical hospitalisation, the non-use of parenteral nutrition and fewer interruptions of ENT. ${ }^{27}$

When considering the indicators for ENT, only the presence of diarrhoea, the presence of an abdominal distension, together with a cumulative deficit of energy, were able to predict HT and MVT.

The limitations of this study can be considered by the fact that this was a retrospective study, as well as the dependency on information from the medical records, together with the sample size that is small and this may well be why some variables were not significant, and the difficulties of comparisons with other studies of children with cancer in a paediatric intensive care unit. These limitations were justified by a lack of evidence in this particular population and the difficulties in studying the outcomes and the secondary peculiarities of children with cancer. You can also add the fact that in this study, we have used prediction formulas for the calculation of their energy needs, instead of indirect calorimetry, since this is still not a reality in most PICUs.

The key point is that this is the first study to examine specifically ENT in oncology children in PICU and they have cumulative energy and protetin deficits. Diarrhoea, younger age and the cumulative caloric deficiencies were HT predictors. On the other hand, abdominal distention and younger age were associated with a higher MVT.

\section{Conclusion}

It should be noted that there is still a wide variation between practices on critically ill children when using an ENT procedure. Thus, the construction of nutritional protocols and the establishment of a multidisciplinary team of nutritional therapists can be suggested. These propositions have been identified by our team, as part of the strategies to improve clinical outcomes in a PICU. The findings of this study have reinforced the importance for the prevention of gastrointestinal complications, such as diarrhoea, as well as the need to evaluate the risks of children presenting worse clinical outcomes on the severities of this unfortunate disease. More studies with children that are affected by a serious condition of cancer should be made. In particular, by relating the quality indicators for ENT can also help to understand the predictors of caloric and protein deficits, when considering the peculiarities of children with a chronic disease like cancer.

\section{Abbreviations}


ENT: Enteral Nutritional Therapy; PICU: Paediatric Intensive Care Unit; HT: Hospitalisation Time; MVT: Mechanical Ventilation Time; PNT: Parenteral Nutritional Therapy; TNE: Transnasal Esophagoscopy; IQR: Interquartile Range; BMI: Body Mass Index; NGC: Nasogastric Catheter; PPC: Post Pyloric Catheter; OR: Odds Ratio;Cl: Confidence Interval;LOS: Length of Stay.

\section{Declarations}

\section{Competing Interest:}

The authors declare that they have no conflict of interest.

\section{Funding:}

There has been no significant financial support for this study.

\section{Acknowledgments:}

The authors would like to thank the research support of the National Institute of Cancer.

Author's Contributions: WVA, WAFP and PCP participated in the design and planning of the study, in data collection, critical analysis of results, drafting and reviewing the final manuscript. TPP, NBP and RBM participated analyzing the results and drafting the manuscript. All authors have read and approved the manuscript.

\section{Availability of data and materials:}

The datasets generated and/or analysed during the current study are not publicly available due for ethical reasons. Authors are committed to maintaining the confidentiality of information when requesting the data usage commitment term. but are available from the corresponding author on reasonable request.

\section{References}

1. Joffe A et al. Nutritional support for critically ill children. Cochrane Database Syst Rev. 2016; 5:CD005144.

2. Mara $\mathrm{J}$ et al. An evaluation of enteral nutrition practices and nutritional provision in children during the entire length of stay in critical care. BMC Pediatr. 2014; 14:186. 
1. Mehta, N.M., Skillman, H.E., Irving, S.Y., Coss-Bu, J.A., Vermilyea. S. et al (2017). Guidelines for the Provision and Assessment of Nutrition Support Therapy in the Pediatric Critically III Patient: society of Critical Care Medicine and American Society for Parenteral and Enteral Nutrition. Pediatr Crit Care Med. 18(7), 675-715.

2. Força-Tarefa em Nutrição Clínica. Comitê de Nutrição ILSI BRASIL. Indicadores de qualidade em terapia nutricional: Aplicação e Resultados. 1.ed. pp. 156. São Paulo: ILSI; 2010.

3. De Oliveira Iglesias SB et al. Enteral nutrition in critically ill children: are prescription and delivery according to their energy requirements? Nutr Clin Pract. 2007; 22:233-239.

4. Lee H et al. Avoidable Causes of Delayed Enteral Nutrition in Critically III Children. J Korean Med Sci. 2013;28:1055-1059.

7. Askegard-Giesmann JR\& Kenney BD. Controversies in nutritional support for critically ill children. Semin Pediatr Surg. 2015;24: 20-24.

1. Tume L, Latten L, Darbyshire A. An evaluation of enteral feeding practices in critically ill children. Nurs Crit Care. 2010;15:291-299.

2. López-Herce J. Gastrointestinal complications in critically ill patients: what differs between adults and children? Curr Opin Clin Nutr Metab Care. 2009; 12:180-185.

3. De Onis M et al. Development of a WHO growth reference for school-aged children and adolescents. Bull World Health Organ. 2007; 85:660-667.

4. World Health Organization. WHO child growth standards: length/height-for-age, weight-for-age, weight-for-length, weight-for-height and body mass index-for-age; methods and development. Geneva: WHO Press; 2006.

5. World Health Organization. WHO Anthro (version 3.2.2, January 2011) and macros. http://www.who.int/childgrowth/software/en/ (accessed May 2016).

6. Lemos PSM, de Oliveira FLC\& Caran EMM. Nutritional status of children and adolescents at diagnosis of haematological and solid malignancies. Rev Bras Hematol Hemoter. 2014; 36:420-423.

7. Pollack MM, Ruttimann UE\& Getson PR. Paediatric risk of mortality (PRISM) score. Crit Care Med. 1988; 16:1110-1116.

8. Holliday MA\& Segar WE. The maintenance need for water in parenteral fluid therapy. Pediatrics. 1957; 19:823-832.

9. Garófolo A. Diretrizes para terapia nutricional em crianças com câncer em situação crítica. Rev. Nutr. 2005; 18:513-527.

10. Instituto Nacional de Câncer (2011) Consenso Nacional de Nutrição Oncológica. http://www1.inca.gov.br/inca/Arquivos/consenso_nutricao_vol2.pdf(accessed May 2016).

11. Meyer R et al. The impact of enteral feeding protocols on nutritional support in critically ill children. $J$ Hum Nutr Diet. 2009;22:428-436. 
12. Hulst $\mathrm{JM}$ et al. The effect of cumulative energy and protein deficiency on anthropometric parameters in a paediatric ICU population. Clin Nutr. 2004; 23:1381-1389.

13. Guarino A et al. European Society for Paediatric Gastroenterology, Hepatology, and Nutrition/European Society for Paediatric Infectious Diseases evidence-based guidelines for the management of acute gastroenteritis in children in Europe: executive summary.J Pediatr Gastroenterol Nutr. 2008; 46:S81-122.

14. Hosmer DW, Lemeshow S.Applied Logistic Regression. New York: Wiley; 1989.

15. Tume LN, Bickerdike A, Latten L, Davies S, Lefèvre MH ${ }^{5}$ Nicolas GW, Valla FV. Routine gastric residual volume measurement and energy target achievement in the PICU: a comparison study. Eur J Pediatr. 2017;176(12):1637-1644.

16. Costa CAD, Tonial CT, Garcia PCR. Association between nutritional status and outcomes in criticallyill paediatric patients - a systematic review. J Pediatr (Rio J). 2016; 92:223-229.

17. Mikhailov TA et al. Early Enteral Nutrition is Associated with Lower Mortality in Critically III Children. JPEN J Parenter Enteral Nutr. 2014; 38:459-466.

18. Skillman HE\& Wischmeyer PE. Nutrition therapy in critically ill infants and children. JPEN J Parenter Enteral Nutr. 2008; 32:520-534.

19. Moreno YMF et al. Problems with Optimal Energy and Protein Delivery in a Paediatric Intensive Care Unit. Nutr Clin Pract. 2016; 31:673-680.

20. Hulst $\mathrm{J}$ et al. Malnutrition in critically ill children: from admission to 6 months after discharge. Clin Nutr. 2004; 23:223-232.

21. Manaf ZA et al. Delivery of enteral nutrition for critically ill children. Nutr Diet. 2013; 70:120-125.

22. Haugen HA, ChanLN\&Li F. Indirect calorimetry: a practical guide for clinicians. Nutr Clin Pract. 2007; 22:377-388.

23. Kyle UG et al. Is Indirect Calorimetry a Necessity or a Luxury in a Paediatric Intensive Care Unit? JPEN J Parenter Enteral Nutr. 2012; 36:177-182.

\section{What Is Known}

- For children in an intensive care unit enteral nutrition therapy (ENT) has been recommended as the preferred option for a nutritional intervention.

- Gastrointestinal complications are associated with the effectiveness of ENT and these may affect the clinical outcomes in a PICU.

\section{What Is New}

- It is the first study about ENT practices in PICU with oncological children exclusively.

- The presence of diarrhoea, abdominal distension and a cumulative deficit of energy were able to predict hospitalisation time (HT) and mechanical ventilation time (MVT). 


\section{Figures}

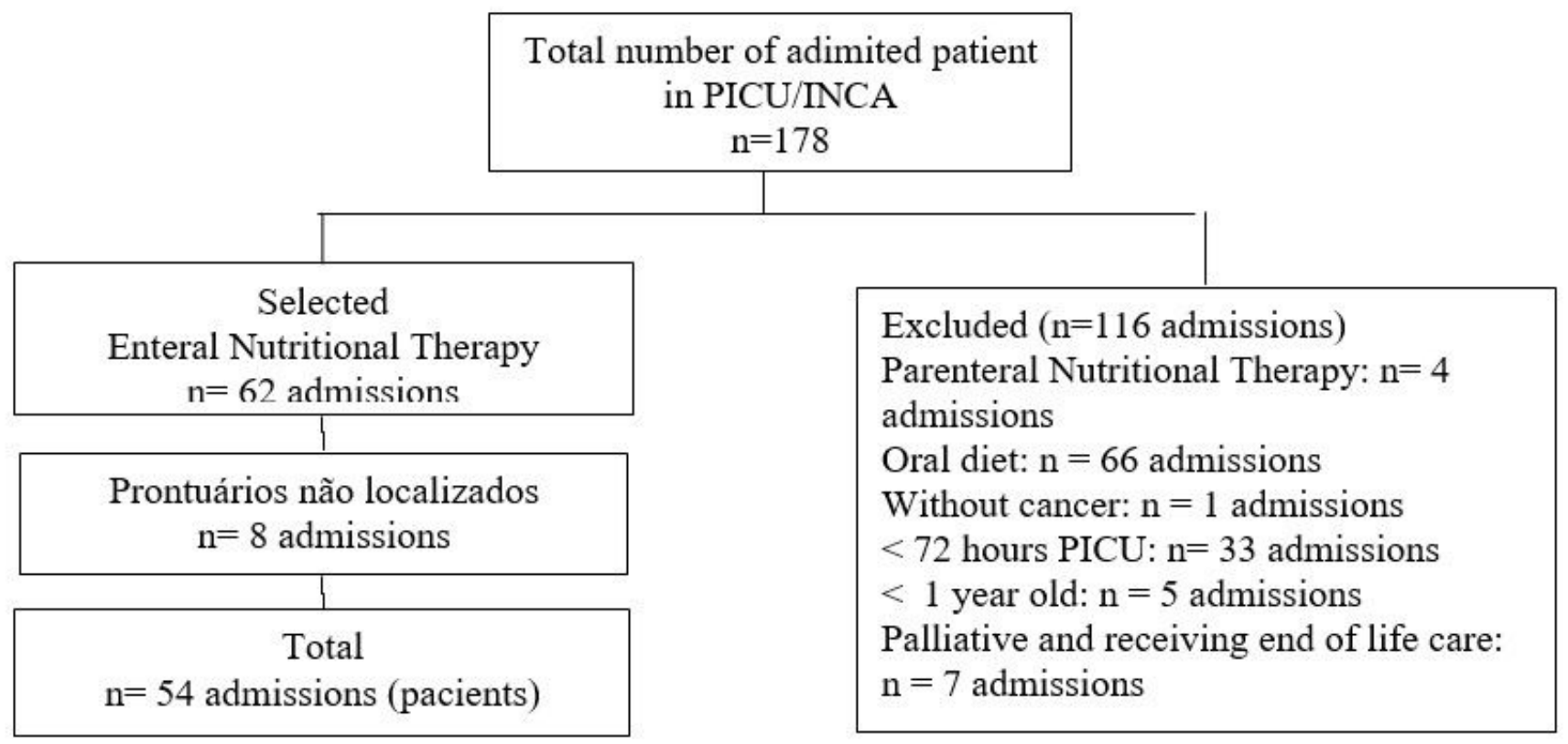

\section{Figure 1}

Flowchart of obtaining the sample PICU: Pediatric Intensive Care Unit; INCA: Instituto Nacional de Cancer (INCA/National Cancer Institute); 